\title{
Erratum
}

\section{Erratum to "Theoretical and Experimental Verification of Dynamic Behaviour of a Guided Spline Arbor Circular Saw"}

\author{
Ahmad Mohammadpanah $\mathbb{D}^{1}$ and Stanley G. Hutton $\mathbb{D}^{2}$ \\ ${ }^{1}$ FPInnovations, 2665 East Mall, Vancouver, BC, Canada \\ ${ }^{2}$ Department of Mechanical Engineering, The University of British Columbia, Vancouver, BC, Canada V6T $1 Z 4$ \\ Correspondence should be addressed to Ahmad Mohammadpanah; ahmadpa20@gmail.com \\ Received 4 February 2018; Accepted 14 February 2018; Published 13 March 2018 \\ Copyright (C) 2018 Ahmad Mohammadpanah and Stanley G. Hutton. This is an open access article distributed under the Creative \\ Commons Attribution License, which permits unrestricted use, distribution, and reproduction in any medium, provided the \\ original work is properly cited.
}

In the article titled "Theoretical and Experimental Verification of Dynamic Behaviour of a Guided Spline Arbor Circular Saw" [1], there were errors in the names of the authors of references $[15,16]$, and reference $[15]$ was incomplete. The references should be corrected as follows:

[15] K. Orlowski and T. Ochrymiuk, "A newly-developed model for predicting cutting power during wood sawing with circular saw blades," Maderas: Ciencia y tecnología, 2017, vol. 19, no. 2, pp. 149-162. DOI: 10.4067/S0718-221X2017005000013.

[16] A. Kaczmarek, K. Orlowski, and L. Javorek, "Comparison of natural frequencies of a circular saw blade obtained empirically and with FEM," Annals of Warsaw University of Life Sciences Forestry and Wood Technology, pp. 46-50, 2016.

\section{References}

[1] A. Mohammadpanah and S. G. Hutton, "Theoretical and experimental verification of dynamic behaviour of a guided spline arbor circular saw," Shock and Vibration, vol. 2017, Article ID 6213791, 12 pages, 2017. 


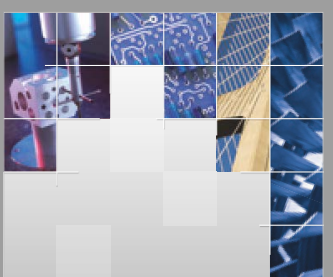

\section{Enfincering}
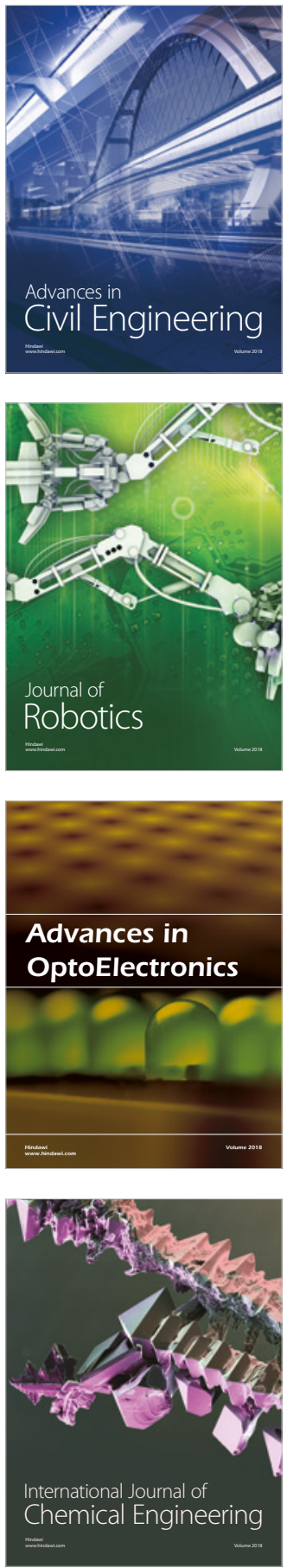

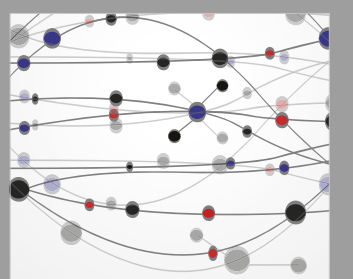

\section{Rotating \\ Machinery}

The Scientific World Journal

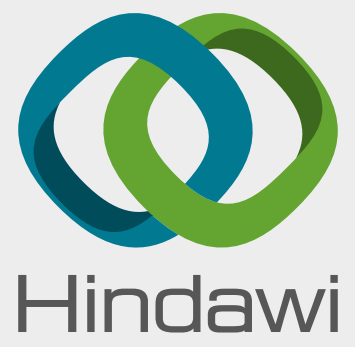

Submit your manuscripts at

www.hindawi.com
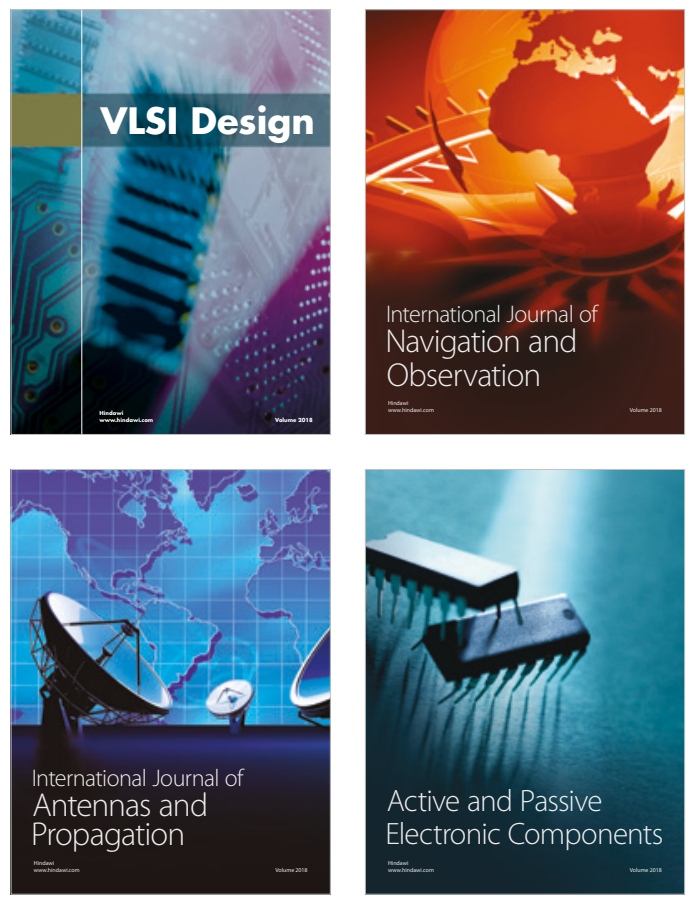
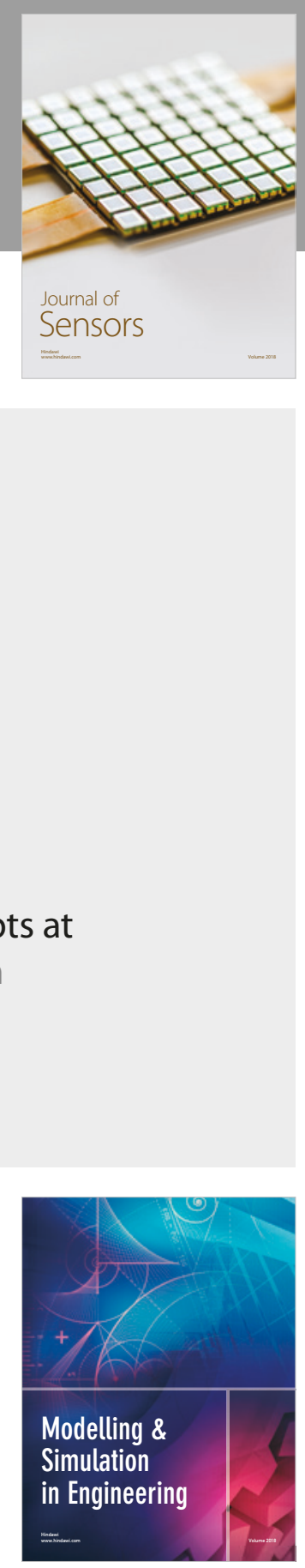

\section{Advances \\ Multimedia}
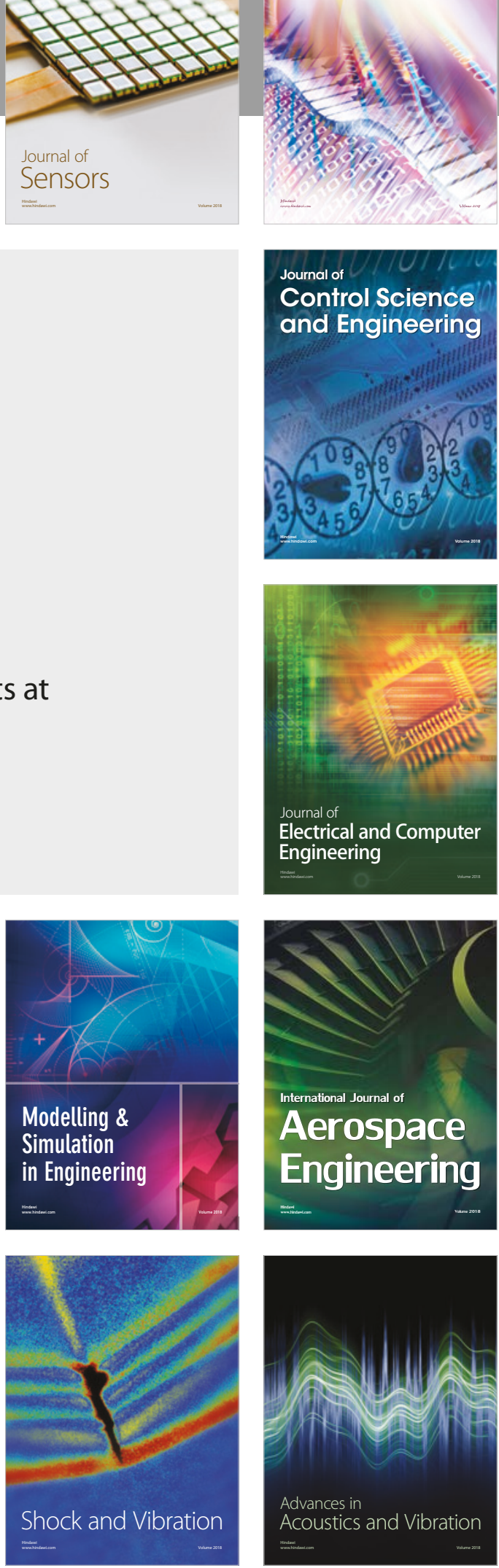